\title{
SHAKESPEARE APAIXONADO COMO INTRODUÇÃO A SHAKESPEARE
}

Déborah Scheidt ${ }^{1}$

\section{RESUMO}

Shakespeare Apaixonado pode constituir-se uma excelente porta de entrada para o universo shakespeareano. O filme desmistifica a figura de Shakespeare como gênio inacessível, mostrando de maneira bastante original o período histórico, o contexto literário e o modus operandi do teatro elisabetano.

Palavras-chave: Shakespeare, metodologia de ensino, cinema

\begin{abstract}
Shakespeare in Love can be an excellent entrance path into Shakespeare's world. The film reverses the notion of Shakespeare as an untouchable genius, showing the historical period, the literary context and the modus operandi of elisabethan drama from a very original perspective.
\end{abstract}

Key words: Shakespeare, teaching methodology, cinema

\section{MEDO DE SHAKESPEARE}

Vejamos quais poderiam ser, do ponto de vista de um público leigo, algumas idéias pré-concebidas a respeito de Shakespeare, idéias essas provindas do senso-comum e, assim sendo, capazes de intimidar possíveis leitores, dificultando o trabalho do professor de literatura ou de língua inglesa.

Um primeiro empecilho, particularmente em se tratando de um falante de inglês como segunda língua, é o próprio inglês renascentista, o qual, ainda que reconhecível, costuma causar estranheza ao leitor contemporâneo.

Também a forma poética dos textos pode afastar candidatos a leitor. Mesmo nas melhores traduções, tentar entrar no universo lingüístico de Shakespeare pode converter-se em uma árdua tarefa, pelo rebuscamento da linguagem e artifícios poéticos sofisticados.

\footnotetext{
${ }^{1}$ Déborah Scheidt é mestre em Letras -Literaturas de Língua Inglesa e professora no Centro Universitário Campos de Andrade (UNIANDRADE) e Faculdades Curitiba.
} 
Outro fator que pode engrossar esta lista é que, apesar de Shakespeare ser repetidamente denominado de escritor "universal” ou seja, um exímio detector dos sentimentos humanos mais básicos - como o amor, a inveja, a cobiça, a amizade, a dúvida, a honra, o ódio, a deslealdade...-, suas peças foram escritas “sob encomenda” para um público e uma maneira de fazer teatro muito particulares. Por estarmos distanciados quase 500 anos desse público e desse teatro, podemos encontrar barreiras cognitivas ao fazer uma leitura das peças com olhos contemporâneos: o que fatalmente faria rir ou chorar uma platéia elisabetana, pode não corresponder perfeitamente ao que hoje consideramos cômico ou trágico. Também o que hoje nos parece inverossímil poderia ser perfeitamente lógico naquela época - e vice-versa.

Por fim, muitas pessoas sentem-se propensas a evitar Shakespeare, intimidadas simplesmente pelo mito de gênio sagrado e inquestionável da literatura universal — e por conseqüência inacessível - que se construiu, ao longo de séculos e séculos de “bardolatria”, ao seu redor.

\section{O NERVOSISMO DO PRIMEIRO ENCONTRO}

É certo que prática de leitura, persistência e orientação adequada podem facilitar a transposição de tais dificuldades. Antes disso, porém, o desafio do professor consiste em preparar o terreno para o primeiro encontro do leitor com Shakespeare, utilizando-se de artifícios que não só diminuam sua apreensão, mas também despertem sua curiosidade.

A respeito da importância de se proporcionar um embasamento adequado para o estudo de uma obra literária, Joanne Collie e Stephen Slater afirmam que

para um aluno prestes a explorar o território desconhecido de uma nova obra literária, o primeiro encontro com essa obra pode ser crucial. As primeiras impressões podem influenciar seus sentimentos, afetando o processo como um todo. A reação mais provável por parte do aluno é uma mistura de curiosidade, excitação e apreensão. O papel do professor nesse processo deve ser o de criar um clima de aventura, e ao mesmo tempo, oferecer suporte ao aluno, proporcionando-lhe uma sensação de segurança. [...] O primeiro passo consiste em tentar trazer o aprendiz para dentro do 
texto o mais rápido possível, para que ele sinta-se motivado a continuar a leitura por seus próprios meios. (COLLIE \& SLATER, 1987, p. 16, minha tradução).

Barbara Heliodora, considerada a maior estudiosa de Shakespeare no Brasil, corrobora a opinião acima ao afirmar que "somos privilegiados por vivermos no século XX, quando toda uma pesquisa em torno do palco elisabetano, suas técnicas, recursos, convenções, permitiu que tivéssemos a oportunidade de ver montagens consideravelmente mais próximas das originais do que viram os que viveram nos séculos XVIII e XIX.” (HELIODORA, 2004, p. 46) Esse conhecimento contextual, de acordo com Heliodora, nos permite desfazer a idéia de Shakespeare como “lenda” e visualizar "um homem de carne e osso que nasceu, viveu e morreu em determinadas circunstâncias, de modo que não é possível dizer que, como Palas Atena, ele tenha nascido pronto, adulto e armado, da cabeça de Zeus.” (ibid, p. 15)

Graças a esse tipo de pensamento, afirma Victor Kiernan, a idéia de que a literatura é não-referencial e desconectada do mundo exterior expressa pelos “Novos Críticos” vem mais e mais dando lugar a "outros textos mais férteis" que "tratam dos possíveis elos entre o que Shakespeare escreveu e o ambiente em que viveu.” (KIERNAN, 1995, p.12)

A intertextualidade pode ser definida como a capacidade que uma obra tem de dialogar com outras obras e mídias. Rosa Anna Rizzo articula isso do seguinte modo: “Todos os textos são tecidos com fios provenientes de outros textos, quer seu autor queira, quer não, e portanto a literariedade flui de alguns textos literários e artísticos para outros.” (RIZZO, texto on-line, minha tradução). Ainda de acordo com Rizzo, um plano de trabalho cuidadosamente preparado envolvendo a comparação e o contraste de obras e mídias paralelas pode reduzir a distância temporal e espacial entre textos e fazer com que o aprendiz de literatura aprecie - e até mesmo sinta prazer - em estudar uma obra. (ibid)

As considerações deste tópico são assim sintetizadas por S. J. Burke e C. J. Brumfit, para quem o ensino e a aprendizagem efetivos de literatura envolvem o reconhecimento dos seguintes fatores: 
a) Todo texto está inserido em uma tradição literária e a compreensão literária concreta envolve a consciência de tal tradição.

b) Intertextualidade - as respostas de um leitor a um texto provêm não só daquele texto, mas de toda uma rede de textos que o rodeia;

c) A seleção das obras e da metodologia a ser adotada deve levar em conta o público alvo (faixas etárias, situação cultural, etc.), suas necessidades e habilidades para que ocorra a resposta adequada às obras.

d) Uma obra literária não existe em um vácuo; seu estudo pode e deve ser enriquecido por materiais e mídias paralelos. (BRUMFIT \& BURKE, 1986, p. 175-6)

\section{O PAPEL DO CINEMA}

Dentre esses “materiais e mídias” podemos destacar o cinema. Como afirma Anthony Burgess “a velocidade de ação em Shakespeare, suas rápidas mudanças de cena requerem — se se deseja naturalismo - um veículo tão fluido como o cinema, e foi através dos filmes que Shakespeare acabou sendo revelado para muitas pessoas em nossa época.” (BURGESS, 2001, p. 91)

Enquanto é possível se optar entre versões cinematográficas mais antigas e recentes da maioria das peças e de documentários históricos televisivos, em se tratando de biografias e biografias ficcionalizadas, não se pode dizer o mesmo. Shakespeare Apaixonado (1998, roteiro de Marc Norman e Tom Stoppard, direção de John Madden) veio preencher essa lacuna. O filme recebeu vários prêmios importantes no cenário cinematográfico internacional não só pelo cuidado técnico a ele despendido, mas principalmente por seu caráter inovador.

\section{SHAKESPEARE DE CARNE E OSSO}

A proposta central de Shakespeare Apaixonado é a desmistificação da imagem freqüentemente endeusada de Shakespeare como um gênio sóbrio, de proporções sobre- 
humanas e que se preocupava quase que exclusivamente com sua arte. Já nesse aspecto o filme é um divisor de águas.

O viés humorístico através do qual Shakespeare Apaixonado retrata o dramaturgo e a sociedade elisabetana em muito contribui para este objetivo. O protagonista do filme, Shakespeare, ou Will ${ }^{2}$ (Joseph Fiennes), é um rapaz sagaz e romântico, em início de carreira, que luta para estabelecer seu lugar dentre os dramaturgos elisabetanos e para conseguir as cinqüenta libras esterlinas que o permitiriam ingressar no grupo "Lord Chamberlain’s Men” de Richard Burbage, a mais prestigiada companhia de teatro da época.

Além dos problemas financeiros, Will passa por uma crise em sua capacidade criativa — o afamado “writers' block” - e tem problemas para escrever uma peça cômica encomendada por Philip Henslowe (Geoffrey Rush), o dono da trupe “Lord Admiral's Men”, companhia rival de “Lord Chamberlain’s Men”.

Outro fator que contribui para essa "humanização" do herói do filme são as dificuldades afetivas e sexuais pelas quais o poeta está passando. Apesar das muitas damas que parecem ter recebido seus favores (incluindo “a negra Sue”, “a gorda Phebe” e “Aphrodite Baggot que faz aquilo atrás do Dog and the Trumpet” - p. 16), Will, no início do filme, sente-se privado de uma musa inspiradora. Empolga-se momentaneamente por Rosalina, uma simples costureira da companhia Chamberlain com reputação dúbia, já que além de Will, também é amante de pelo menos dois outros personagens do filme: o próprio Burbage e Mr Tilney, o censor dos divertimentos públicos da rainha.

E, no entanto, é Viola De Lesseps (Gwyneth Paltrow), filha de Sir Robert De Lesseps, comerciante rico, porém sem berço nobre, que acaba atraindo a atenção de Will, durante um baile na casa de seu pai. Essa cena, aliás, dialoga com aquela em que Romeu apaixona-se por Julieta na mansão dos Capuleto e particularmente com as imagens do baile no clássico Romeu e Julieta de Franco Zefirelli, de 1968, uma das muitas referências paródicas do filme. As cenas em que Will conhece Viola e por ela se apaixona são, via de regra, deliciosamente líricas e cômicas.

\footnotetext{
${ }^{2}$ A partir deste ponto, menções a "Shakespeare" vão referir-se ao personagem histórico e a "Will" ao personagem ficcional de Norman e Stoppard.
} 


\section{FANTASIANDO SOBRE A COMPOSIÇÃO DE ROMEU E JULIETA}

Ao incluir um caso de amor para Will, os roteiristas do filme aproveitam para introduzir na trama detalhes sobre a autoria de Romeu e Julieta e a origem das cinqüenta libras que iriam financiar o ingresso de Shakespeare na companhia de Burbage. Assim como o próprio Shakespeare costumava fazer, Norman e Stoppard colocam uma história dentro de outra quando entrelaçam as aventuras amorosas (criadas por eles) do ardente, malandro e às vezes atrapalhado Will à própria trama da peça Romeu e Julieta original de Shakespeare. Comparando-se, por exemplo, o diálogo que ocorre pela manhã após a primeira noite de amor do casal com o diálogo efetivamente incorporado à peça de Shakespeare, tem-se uma brincadeira meta-ficcional sobre a inspiração criativa e a noção do artista incrementando os acontecimentos do dia-a-dia para que se tornem poéticos:

No filme:

Viola: Não vai me abandonar?

Will: Preciso. Veja como a luz da janela está pálida.

Viola: É o luar!

Will: Não, o canto do galo me despertou.

Viola: Foi a coruja - venha para a cama...

Will: Oh, Henslowe que espere.

Viola: O Sr. Henslowe?

Will: Ele que se dane esperando pelo manuscrito!

Viola: Oh...não, não!

Will: Temos tempo. Ainda está escuro.

Viola: Já é dia claro! O galo está nos avisando.

Will: Foi a coruja. Acredite, amor, foi a coruja.

Viola: Você nos deixaria sem uma cena para ensaiar hoje?

(NORMAN \& STOPPARD, 1999, p. 75)

Na peça:

Julieta: Mas já quer ir? Ainda não é dia.

Foi só o rouxinol, não a cotovia

Que penetrou seu ouvido assustado.(...)

Verdade, amor; foi só o rouxinol.

Romeu: Foi o arauto do dia, a cotovia,

E não o rouxinol. Veja os clarões

Que já rendem as nuvens no leste (...)

Julieta: $\quad$ Essa luz não é o dia, amor; eu sei.

É um meteoro que o sol exalou (...)

Fica um pouco; não é preciso ir.

Romeu: Então. Que eu fique, e seja executado;

Concordo, se é assim que você quer. (...)

Não ouvi cotovia, cujo canto reboa até a 


\author{
cúpula do céu. \\ Que me importa partir. Quero ficar. \\ Conversaremos, amor; não é aurora. \\ Julieta: $\quad$ É sim, é sim; você tem de ir embora. \\ É a cotovia que canta assim, tão mal.
}

\section{SHAKESPEARE PÓS-MODERNO}

O filme utiliza explicitamente os próprios artifícios dramáticos shakespereanos. O exemplo mais claro é o fato de Viola, como amante do teatro, travestir-se de ator para poder participar da peça de Will, o que será discutido em maior detalhe mais adiante. O transtorno causado pela troca de identidades (Will/Marlowe) é outra técnica muito utilizada por Shakespeare não só em suas comédias, como também nas tragédias.

Simultaneamente, a comicidade do enredo também é trabalhada através de detalhes anacrônicos, tais como a caneca-souvenir sobre a mesa de Will com as inscrições “Lembrança de Stratford Upon Avon”, a cena no divã do Dr. Moth, "boticário, alquimista, astrólogo, vidente, intérprete de sonhos e conselheiro da psique" e o "happy hour" anunciado pelo produtor da peça, Mr. Fennyman, após a briga entre as duas companhias rivais. A taberna em que os personagens se encontram tem várias características do pub inglês contemporâneo: um barman que serve drinks elaborados à maneira do século XX e é quase um confidente dos fregueses e um menu elisabetano "sofisticado", incluindo "o especial de hoje: pé de porco temperado com vinagre de zimbro, servido com uma panqueca de trigo sarraceno".

Os aspectos que envolvem a criação, produção e atuação teatral elisabetanos nos soam bastante atuais: rivalidade e admiração entre dramaturgos e produtores, os momentos de crise afetando a bilheteria, o sonho do estrelato, a vaidade dos "super-stars", as contendas com a censura, as trivialidades, peripécias e confusões dos bastidores da produção (o “making-of” da peça), a maximização dos lucros... 


\section{EVENTOS (QUASE) HISTÓRICOS}

No entanto engana-se quem julga que, em meio a tantos eventos fantasiosos, hilários e paródicos, Shakespeare Apaixonado não passa de mero entretenimento sem um compromisso mais sério com a veracidade. Comparando-se o roteiro o que se sabe sobre a arte e a vida de Shakespeare, a dramaturgia e a sociedade da época, nota-se que o filme também se apóia sobre uma base histórica sólida.

O tempo da narrativa - 1593 — é um bom exemplo desse mix histórico-ficcional que permeia o filme. Em 1593 realmente houve um agravamento na epidemia de peste negra em Londres, os teatros foram fechados e Christopher Marlowe morreu. Os ataques dos puritanos (pregadores calvinistas contra qualquer tipo de diversão pública) nas portas dos teatros ocorriam com freqüência (até que em 1640, sob a liderança de Oliver Cromwell, eles conseguiriam fechar os teatros de Londres por quase vinte anos).

Outros eventos mostrados no filme, no entanto, apenas se aproximam dos períodos em que realmente ocorreram ou devem ter ocorrido. A maioria dos estudiosos aceita o fato de que Romeu e Julieta só foi lançada em 1594. Edmund Tilney, o "Mestre dos Divertimentos”, censor e empresário para espetáculos a serem realizados na corte (HONAN, 2001, p. 147), que tem um papel crucial na peça, realmente existiu, porém esteve no cargo de 1597 a 1610.

\section{PERSONAGENS (REALMENTE) HISTÓRICOS}

Por outro lado, Shakespeare realmente deixou sua esposa e filhos em Stratford para tentar a sorte em Londres. Ele realmente preferia morar nos bairros fervilhantes próximos aos teatros em que trabalhava e escreveu peças para as companhias de Henslowe e Burbage. Além disso, em 1594 Shakespeare finalmente torna-se membro participante da companhia “Lord Chamberlain’s Men”, mediante o pagamento de 50 libras esterlinas. Antes disso teria sido um mero "trabalhador contratado", o que "não lhe permitiria ter seu nome listado entre os principais atores de uma trupe.” (HONAN, 2001, p. 144) 
Além do próprio Will, vários outros personagens provêm dos livros de história. Talvez o mais relevante deles para o filme, depois de Will, seja Phillip Henslowe. O proprietário do teatro "The Rose” mantinha um diário onde anotava todas suas receitas e despesas (hoje propriedade do Dulwich College, London). Nesse diário consta que em 1592 Henslowe endividou-se ao reformar o teatro e construir um palco coberto. Também aparece lá que o Rose esteve fechado nessa época devido à peste e que Edward Alleyn, o ator principal da trupe “The Admiral's Men” e genro de Henslowe, saiu com seus homens em turnê pelo interior da Inglaterra, como forma de subsistência alternativa. (HONAN, 2001, p. 190-193)

Outro personagem histórico extremamente relevante no filme é Christopher Marlowe. Marlowe e Shakespeare nasceram no mesmo ano (1564), porém, como se pode ver no filme, enquanto Shakespeare ainda era um dramaturgo inexperiente, Marlowe já tinha sua reputação bem sedimentada. Essa fama transparece nas várias menções a Marlowe no decorrer do filme e no fato de que os participantes dos testes para a peça de Henslowe (exceto Viola) escolhem recitar versos de Dr. Faustus de Marlowe: "Foi este o rosto que lançou mil navios ao mar e incendiou as altíssimas torres de Tróia?” (p. 35)

O sentimento de Will em relação a Marlowe é, ao mesmo tempo, de inveja e admiração, já que muitos acreditam que, não fosse a misteriosa morte de Marlowe numa taverna londrina (suspeita-se que estaria envolvido em espionagem), este tivesse talvez superado Shakespeare quanto à qualidade de sua obra. O encontro dos dois dramaturgos no bar onde Marlowe dá a Will dicas para a primeira versão de Romeu e Julieta, recria, de forma cômica, a intertextualidade que realmente existe entre os dois. Will confessa a Viola quando ouve falar da morte de Marlowe: "Havia o toque de Marlowe no meu Tito Andrônico e meu Henrique VI foi uma casa construída sobre o alicerce dele.” (p. 113) Shakespeare nunca chegou a freqüentar uma universidade e apesar de não ser um “university wit”, como dramaturgos como Marlowe e Kyd eram chamados, Shakespeare faz referências a um número maior de fontes literárias externas em suas peças do que aqueles.

Dos personagens-atores que aparecem no filme Edward Alleyn, Richard Burbage e Will Kempe foram, de fato, renomados atores elisabetanos. Alleyn era conhecido por sua 
interpretação competente dos principais papéis criados por Marlowe, como o filme deixa bem claro pela sua entrada triunfal no The Rose: "Sou Hierônimo! Sou Tamburlaine! Sou Fausto! Sou Barrabás, o Judeu de Malta” e também alguns de Shakespeare: “— ah, sim, senhor Will, e sou Henrique VI.”

Shakespeare escreveria seus principais papéis trágicos, Hamlet entre eles, para Burbage que se tornaria seu sócio nos próximos anos. Na cena em que a peça de Will Os Dois cavalheiros de Verona, está sendo encenado no palácio da rainha, Burbage faz o papel de Proteus, enquanto que Kempe aparece representando Launce, um dos palhaços da peça, com seu cachorro Crab.

O menino fascinado por sangue que delata a presença de Viola no palco é John Webster, 15 anos mais jovem que Shakespeare e que faria muito sucesso com peças tais como O Demônio Branco e A Duquesa de Malfi — textos conhecidos pelo teor violento e grotesco.

\section{OS MITOS ELISABETANOS}

A Rainha Elizabeth que aparece no filme também é um bom exemplo de tratamento humorístico bem-sucedido dado um personagem histórico. A admiração da soberana pela arte, sua disposição para patrocinar eventos artísticos e seu espirituosidade, às vezes cruel, ficam bem evidentes em todas as cenas em que Elizabeth aparece. Assim como uma comédia não poderia deixar de explorar alguns dos muitos mitos que perspassam a figura da "rainha virgem". Uma dessas crendices diz que ela seria, na verdade, um homem (mito retomado quando Elizabeth diz ao Sr. Tilney a respeito de Viola “Conheço bem a mulher que exerce profissão de homem, sim, juro por Deus que sei tudo a esse respeito” p. 147). A crença de que a rainha às vezes se disfarçasse de plebéia para viver experiências “comuns” se materializa nas cenas finais, quando ela aparece como a figura mascarada que estava assistindo Romeu e Julieta, mesmo podendo contar com o privilégio de uma apresentação “avant-premiére” especial para si mesma e sua corte no palácio real. Até mesmo o episódio do cavalheiro que teria estendido sua própria capa para que a rainha 
atravessasse uma poça de lama sem emporcalhar os sapatos é recriado no filme - porém ao inverso.

\section{AS CASAS DE ESPETÁCULO}

Shakespeare Apaixonado é também um excelente meio de conhecermos um pouco mais sobre o teatro elisabetano e suas convenções. As casas de espetáculo mencionadas, The Rose e The Curtain eram as mais importantes da época. O prédio do The Curtain aparece no filme com seu formato arredondado: “esse grande $\mathrm{O}$ de madeira” nas palavras do próprio Shakespeare. Poder visualizar a constituição dessa arquitetura teatral é crucial para o leitor que deseje compreender por que Shakespeare escreveu suas peças do modo como o fez. As apresentações aconteciam a céu aberto e a impossibilidade de se iluminar ou escurecer o ambiente, por exemplo, obrigam as falas das personagens a transmitir todos os detalhes - daí o tratamento cuidadoso dos pormenores no texto.

Os três tipos de palco utilizados ficam bem visíveis no filme. O palco externo (palco "avental”) que se estende para o grande pátio onde ficava o público, praticamente trazia a platéia para dentro da encenação. Havia também o palco interno, para cenas mais íntimas e o palco superior, imprescindível na famosa cena do balcão e usados também como muralhas de castelo. Outros recursos incluíam alçapões superiores e inferiores. Os superiores podiam ser úteis, por exemplo, quando algum deus precisava descer à Terra e os inferiores (Will cai em um deles durante a briga com Burbage) para representar o inferno ou covas em cemitérios.

Os espaços destinados ao público também ganham destaque no filme. O teatro, fica bem claro, servia a todas as classes sociais, não sem, no entanto, as devidas separações: o pátio onde ficavam as pessoas comuns e as galerias para os mais afortunados, que podiam também alugar almofadas, como a mente comercial de Mr Fennyman calcula: "Seriam — quantos? - quinhentos lugares na platéia a dois pence cada, além de quatrocentos nas galerias a três pence - um penny a mais por poltrona acolchoada, digamos duzentas poltronas acolchoadas, duas apresentações ...” (p. 10). Outro detalhe importante: não era de 
bom tom que mulheres respeitáveis de origem nobre freqüentassem casas públicas de espetáculos - a alternativa era que o fizessem mascaradas, como exemplificado pela própria rainha.

\section{AS CONVENÇÕES TEATRAIS}

O filme privilegia bastante a relação íntima entre os atores elisabetanos e sua platéia e a necessidade premente de se vir ao encontro das expectativas desse público, como bem coloca o Sr. Henslowe sobre as perspectivas de sucesso de Romeu e Ethel, a filha do Pirata: “Atrairá multidões - troca de identidades, um naufrágio, um rei dos piratas, participação de um cachorro e o amor triunfante no fim.” (p. 9)

Como afirma Anthony Burgess

“a luz do dia iluminava a platéia, a platéia cercava os três lados do palco, uma pequena parte até se sentava no palco. O ator moderno, separado da platéia por refletores e escuridão, pode fingir que ela é uma fila de repolhos, e não de pessoas. Mas isso não acontecia comum ator elisabetano: ele tinha que estabelecer contato com o seu público que era crítico, às vezes turbulento, certamente formado por pessoas de carne e osso à luz do dia, não abstrações escondidas pela escuridão. Essa platéia tinha de receber o que queria, e, sendo uma mistura, queria coisas variadas - ação e sangue para os iletrados, belas frases e engenho para os almofadinhas, humor sutil para os refinados, palhaçada escandalosa para os não-refinados, assuntos amorosos para as damas, canção e dança para todos. Shakespeare dá todas essas coisas, nenhum outro dramaturgo jamais conseguiu dar tanto.” (BURGESS, 2001, p. 92)

Nesse aspecto vemos novamente os roteiristas Norman e Stoppard se apropriando de técnicas shakespeareanas. Assim como em Romeu e Julieta, Shakespeare Apaixonado tem elementos para agradar tanto aos especialistas em literatura, que podem se deliciar ao identificar as muitas referências shakespeareanas no decorrer do roteiro, quanto aos recém 
iniciados em assuntos elisabetanos e até mesmo ao público que não tem nenhum interesse por Shakespeare, que se diverte simplesmente com as peripécias dos personagens.

A quase inexistência de cenário e adereços no teatro elisabetano também fica evidenciada no filme. Na cena de morte de Romeu e Julieta, por exemplo, todo o mobiliário para caracterizar a tumba dos Capuletos resume-se a um banco. O figurino, por sua vez, ainda que luxuoso, não tinha que estar, necessariamente, adaptado ao tempo e local onde se passava a peça (apesar de italianos, os personagens de Romeu e Julieta vestem-se à moda inglesa).

\section{AS RELAÇÕES DE GÊNERO}

Um outro ponto histórico muito pertinentemente ressaltado pelo filme é a lei elisabetana que proibia as mulheres de pisarem nos palcos. Os papéis femininos, portanto, eram encenados por homens ou rapazes. Para os papéis cômicos, como o da ama de Julieta, não havia muita necessidade de se disfarçar a "masculinidade” do ator, comprovada pela maneira grotescamente hilária pela qual esse papel é desempenhado na peça dentro do filme. Já as heroínas eram representadas por jovens atores que permaneciam no emprego enquanto sua voz continuasse aguda. Fazer com que esses rapazes se sentissem mais confortáveis em seus papéis talvez fosse o objetivo de Shakespeare ao criar, em tantas de suas peças, personagens femininos que se travestem de homens. No filme tal artifício merece o questionamento de Viola: "Mas não gostei tanto de Sílvia. Estava com os dedos vermelhos de tanto brigar e falava como um escolar lendo as lições. O amor no palco jamais será verdadeiro enquanto a lei deste país exigir que nossas heroínas sejam interpretadas por garotos idiotas vestidos de mulher.” (p. 26).

Ao mostrar Viola vestida de homem representando Romeu enquanto Sam, vestido de mulher interpreta Julieta, o filme parodia (e até elabora ainda mais) as complicações criadas por Shakespeare em suas comédias, ao fazer com que um ator homem, vestido de mulher se faça passar por homem, como em O Mercador de Veneza, por exemplo. 
Ao rebelar-se — até certo ponto - contra as convenções sociais referentes à diversão, ao trabalho, à sexualidade e ao casamento, a personagem Viola também torna o filme um campo rico para a análise do papel da mulher na sociedade elisabetana.

\section{SHAKESPEARE INESGOTÁVEL}

Ao apresentar o tema shakespeareano de modo inovador, ao mesmo tempo cômico e sério, e agregando diversos temas - o universo teatral, romance, aventura, história, comédia, relações sociais, o papel da mulher... - Shakespeare Apaixonado é mais uma prova da inesgotabilidade de Shakespeare, além de apresentar-se como uma excelente porta de entrada para aqueles interessados em penetrar no fascinante mundo da obra de Shakespeare.

\section{REFERÊNCIAS}

BURGHESS, Anthony. A Literatura Inglesa. São Paulo: Ática, 2001.

BURKE, S. J. \& BRUMFIT, C. J. “Is Literature Language or Is Language Literature?” In: BRUMFIT C. \& CARTER, R. Literature and Language Teaching. Oxford. OUP: 1986.

COLLIE, Joanne \& SLATER, Stephen. Literature in the Language Classroom: a resource book of ideas and activities. Cambridge, CUP, 1987.

HELIODORA, Barbara. Reflexões Shakespeareanas. Rio de Janeiro: Lacerda, 2004.

HONAN, Park. Shakespeare: Uma Vida. São Paulo: Companhia das Letras, 2001.

KIERNAN, Victor. Shakespeare: Poeta e Cidadão. São Paulo: UNESP, 1995. 
NORMAN, Marc \& STOPPARD, Tom. Shakespeare Apaixonado. Rio de Janeiro: Rocco, 1999.

RIZZO, Anna Maria. Rout Finding and Mind Maps: an intertextual approach to literature. Disponível em:<www.langedizioni.com/varie/aggiornadid/rizzo_bc03/> Acesso em 13 nov. 2005.

SHAKESPEARE, William. Romeu e Julieta. Trad. Bárbara Heliodora. Rio de Janeiro: Nova Fronteira, 1997. 